\title{
Cidade e práticas urbanas: nas fronteiras incertas entre o ilegal, o informal e o ilícito
}

VERA DA SiLVA TELLES e DANIEL VELOSO HiRata

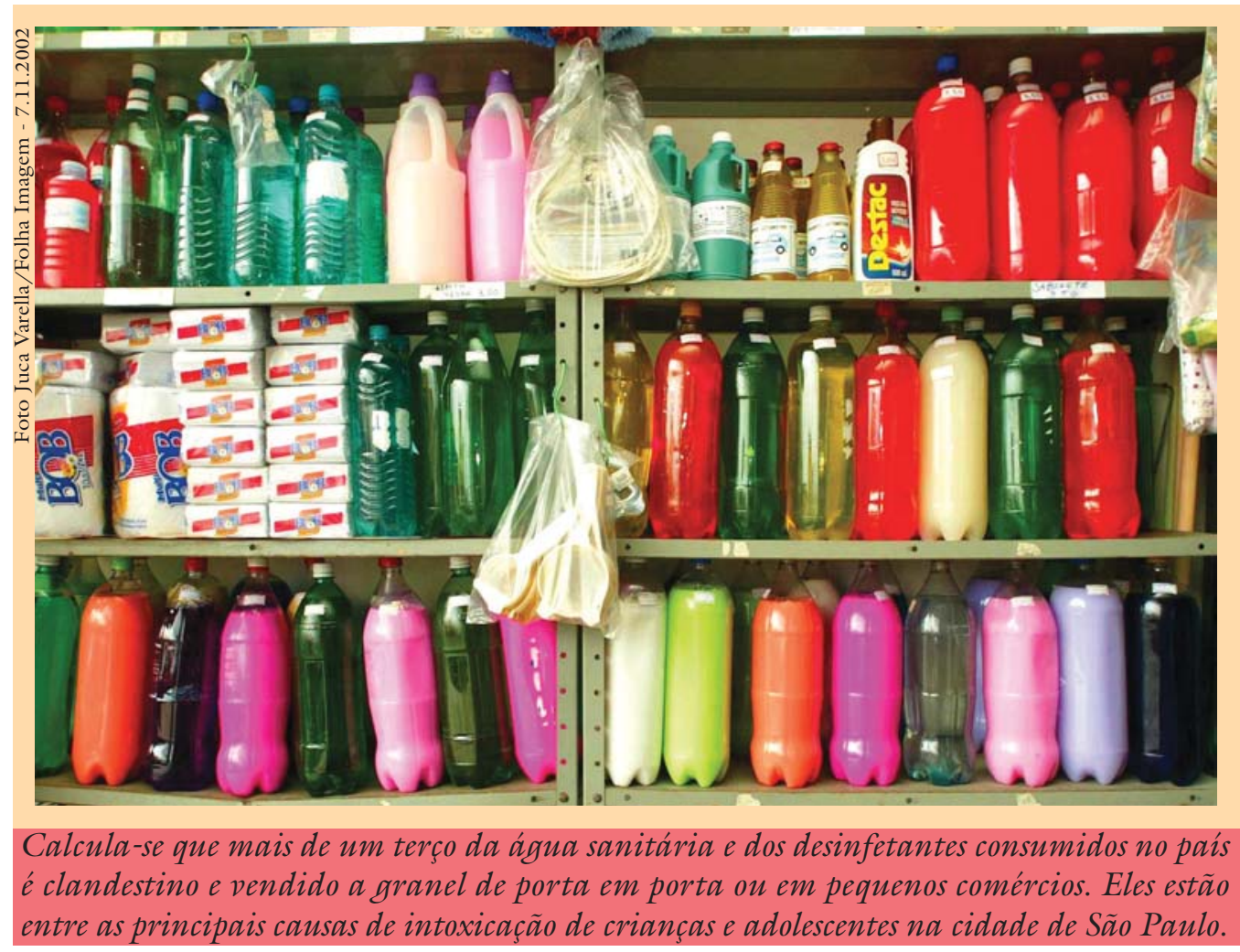

$7 \mathrm{~m}$ artigo de 1997, Ruggiero \& South lançaram mão da metáfora do bazar 1 - "a cidade como bazar" - para descrever as intersecções entre os mercados formais e os mercados informais, ilegais ou ilícitos, tal como vêm se configurando, desde meados dos anos 1980, nas metrópoles dos países centrais do capitalismo contemporâneo. Com evidente intenção polêmica, a metáfora evoca a alteridade nos traços de "orientalismo" associados ao bazar, para chamar a atenção que ele se encontra, doravante, incrustado no núcleo mesmo das modernas (e ocidentais) economias urbanas. Na mira dos autores, está um cenário urbano no qual se expande uma ampla zona cinzenta que torna incertas e indeterminadas as diferenças entre o trabalho precário, o emprego temporário, expedientes de sobrevivência e as atividades ilegais, clandestinas ou delituosas. 
É justamente nas fronteiras porosas entre o legal e o ilegal, o formal e informal que transitam, de forma descontínua e intermitente, as figuras modernas do trabalhador urbano, lançando mão das oportunidades legais e ilegais que coexistem e se superpõem nos mercados de trabalho. Oscilando entre empregos mal pagos e atividades ilícitas, entre o desemprego e o pequeno tráfico de rua, negociam a cada situação e em cada contexto os critérios de aceitabilidade moral de suas escolhas e seus comportamentos. É isso propriamente que caracteriza o bazar metropolitano: esse embaralhamento do legal e do ilegal, esse permanente deslocamento de suas fronteiras sob a lógica de uma forma de mobilidade urbana, "mobilidades laterais", de trabalhadores que transitam entre o legal, o informal e o ilícito, sem que por isso cheguem a se engajar em "carreiras delinqüentes".

O bazar metropolitano, dizem os autores, começou a ganhar forma em meados da década de 1980. No caso da Inglaterra e dos Estados Unidos, momento da virada conservadora de governos que fizeram por desmanchar direitos e garantias sociais, ponto de arranque da precarização do trabalho e redefinição dos mercados urbanos de trabalho. Em termos gerais, anos de reestruturação produtiva e da chamada flexibilização das relações de trabalho que terminou por esfumaçar as diferenças entre trabalho, desemprego e expedientes de sobrevivência, na própria medida em que o assim chamado informal instala-se no coração dos modernos processos produtivos e, no mesmo passo, se expande pelas vias de redes de subcontratação e formas diversas de mobilização do trabalho temporário, esporádico e intermitente, sempre nos limites incertos entre o legal, o ilegal, clandestino ou mesmo ilícito e delituoso (Ruggiero, 2000).

Esses, no entanto, também foram anos em que as atividades ilícitas mudaram de escala, se internacionalizaram e se reorganizaram sob formas polarizadas entre, de um lado, os empresários do ilícito, em particular do tráfico de drogas e que, a cada local irão se conectar (e redefinir a) com a criminalidade urbana comum e, de outro, os pequenos vendedores de rua, que operam à margem da verdadeira economia da droga e transitam o tempo todo entre a rua e a prisão. Esses são os "trabalhadores precários" da droga, que se multiplicam na medida em que varejo se expande e se enreda nas dinâmicas urbanas (cf. Bourgois, 1995), modulação criminosa do capitalismo pós-fordista - criminalidade "just-in-time", define Ruggiero (2000), que responde a variabilidade, oscilações e diferentes territorialidades dos mercados. É justamente nesse ponto que as atividades ilícitas - e não só o tráfico de drogas - passam a interagir com as dinâmicas urbanas e compor o bazar metropolitano nos pontos de intersecção com os igualmente expansivos mercados irregulares, esse terreno incerto em que operam as "mobilidades laterais" de trabalhadores que transitam nas fronteiras borradas entre o trabalho, expedientes de sobrevivência e o ilícito. E também entre a rua e a prisão.

Por certo, as questões propostas por Ruggiero estão longe de dar conta de uma problemática hoje tratada por uma vastíssima literatura sobre o tráfico de drogas em suas várias dimensões, escalas e formas de territorialização. $\mathrm{Na}$ 
verdade, o nosso interesse aqui não é oferecer explicações e muito menos entrar nas suas controvérsias. Interessa sobretudo aqui reter o plano em que Ruggiero apresenta suas questões, colocando a cidade - o bazar metropolitano - em perspectiva e como plano de referência para situar o tráfico de drogas em suas interações com as dinâmicas urbanas modernas.

Bem sabemos que, entre nós, o bazar metropolitano não é exatamente uma novidade. Por isso mesmo, como diz Michel Misse (2006a, p.215-6), a análise deve se deter não tanto na sua oposição a um tipo de cidade moderna que por aqui nunca se realizou completamente, mas sobretudo nas diferentes conjunturas da história urbana, os modos como essa relação entre o informal e o ilegal se configurou no correr dos anos, "as continuidades, descontinuidades e metamorfoses de seus tipos sociais e a reprodução ampliada de seus mercados ilícitos". Em outros termos, esse trânsito entre o informal e o ilegal, quiçá o ilícito, sempre esteve presente e sempre foi importante em cidades marcadas desde longa data por um hoje expansivo mercado informal, sempre próximo e tangente aos mercados ilícitos que também têm uma história que seria importante, em outro momento, reconstituir.

Se há, porém, hoje, a reatualização de uma história de longa duração, há também um deslocamento considerável na ordem das coisas. E é justamente nesse ponto que o bazar metropolitano descrito por Ruggiero interessa para demarcar e pontuar a contemporaneidade e as ressonâncias do que acontece aqui e lá: isso que sempre foi considerado evidência das incompletudes de nossa modernidade, a "exceção do subdesenvolvimento", como diz Chico de Oliveira (2003), não apenas transformou-se em regra (está aí para ficar, sem a superação prometida pelo "progresso"), como se projetou na ponta de um capitalismo que mobiliza e reproduz o "trabalho sem forma", ${ }^{1}$ ao mesmo tempo que fez generalizar os circuitos ilegais de uma economia globalizada nas sendas abertas pela liberalização financeira, a abertura dos mercados e encolhimento dos controles estatais (Naim, 2006), em um tal intrincamento entre o oficial e o paralelo, entre o legal e o ilegal, o lícito e o ilícito que essas binaridades perdem sentido e tornam obsoletas as controvérsias clássicas em torno do formal e o informal (Botte, 2004; Bayart, 2004).

Por outro lado, se a situação brasileira tem que ser vista sob o ângulo dos processos transversais (e globalizados) que a atravessam, também é importante averiguar os modos de sua territorialização, em interação com contingências locais, história e tradições herdadas, assimetrias e desigualdades que lhes são próprias. E é nesse plano que a referência ao bazar contemporâneo também interessa, na medida em que propõe a escala urbana para a descrição das recomposições, redefinições e deslocamentos nas relações entre o informal, o ilegal e o ilícito ou, então, mais especificamente, as recomposições do ilícito em suas interações com as dinâmicas urbanas atuais (cf. Kokoreff, 2007). É nesse plano que gostaríamos de seguir a discussão. 
Antes, vale pontuar duas ordens de questões. Primeiro, a necessária calibragem do ponto da crítica social: a cidade como perspectiva descritiva oferece um plano de referência que permite desativar mitos e ficções em torno do dito Crime Organizado e do Tráfico de Drogas (cf. Kokoreff, 2004 e 2007), essas espécies de entidades fantasmáticas às quais são atribuídas todas e quaisquer mazelas de nossas cidades ou, como sugere Misse (2006c, p.269), os vários apelidos de um Sujeito onipresente e onipotente que responde pelo nome de Violência Urbana e que unifica conflitos, crimes, delitos cotidianos, comportamentos, fatos e eventos os mais disparatados. Voltaremos a isso na parte final deste artigo. Por enquanto, vale dizer que é esse o sentido crítico inscrito no empreendimento descritivo de Ruggiero, ao relançar a noção do "crime como trabalho" e discutir as proximidades e semelhanças, contigüidades e intersecções entre os mercados legais e ilegais, localizando aí, nessas interfaces, a reposição e o engendramento de clivagens sociais, dessimetrias, discriminações diversas e também formas violentas de regulação nos seus modos de segmentação interna. Entre nós, os trabalhos de Misse (2006a,b,c) e Zaluar (2004) mostram o quanto pode ser fecunda a escala urbana para a descrição crítica do ilícito em suas relações e interações com o mercados informais, com os circuitos urbanos de circulação de riqueza e as relações de poder inscritas em seus pontos de intersecção.

Segundo, como já tivemos a oportunidade de discutir em outro momento (Telles \& Cabanes, 2006, p.48), a construção de parâmetros críticos implica ao mesmo tempo a construção de parâmetros descritivos para colocar em perspectiva realidades urbanas em mutação. Em outros termos: reter a cidade como plano de referência supõe uma estratégia descritiva que escape aos termos correntes do debate atual, em grande medida polarizado entre a ênfase nos dispositivos transnacionais do assim chamado crime organizado, de um lado, e, de outro, a discussão do que se convencionou chamar de populações em situação de risco social, expostas à violência e supostamente cativas (ou sob ameaça) das ramificações locais do tráfico de drogas. Entre um e outro, entre fatos e ficções nessas duas pontas do debate atual, há toda uma trama urbana que resta a conhecer. É justamente aqui que se aloja o desafio de compreender o modo como as linhas de força que perpassam os mundos urbanos atuais, muito rapidamente indicados nas páginas anteriores, se entrelaçam e se conjugam nas tramas sociais e nos agenciamentos práticos da vida urbana atual.

Vale aqui dizer que essa é uma questão que corresponde aos nossos próprios percursos de pesquisa. Não somos pesquisadores do tráfico de drogas, tampouco da violência urbana. Nos últimos anos, desde 2001, viemos seguindo os traçados das mobilidades urbanas nas periferias da cidade de São Paulo e, por meio delas, de seus eventos e inflexões no tempo e espaço, buscamos compreender o modo como se processam segregações, assimetrias e desigualdades nos espaços e territórios de uma cidade em mutação (cf. Telles \& Cabanes, 2006). Nesse percurso foram se delineando os perfis de uma cidade perpassada por uma expansiva trama de ilegalidades (nova e velhas) entrelaçadas nas práticas urbanas, 
seus circuitos e redes sociais, e que pareciam colocar uma ordem de questões não mais passíveis de ser tratadas nos termos do tão debatido descompasso entre a cidade legal e cidade real. A rigor, o que exige uma interrogação mais detida são novas mediações e outras conexões que parecem se entrelaçar e se compor nos agenciamentos práticos da vida urbana. Foi esse o nosso ponto de partida.

E é esse o ponto de partida, quer dizer, os agenciamentos práticos da vida cotidiana, para tentar, no que segue, desenrolar os fios (alguns deles) que fazem a urdidura das tramas urbanas. É por essa via, digamos transversal, que pretendemos indicar as capilaridades do tráfico de drogas no mundo social e nas tramas urbanas, tomando como "posto de observação" alguns de seus pontos de ancoramento em um bairro periférico da cidade de São Paulo. Essa é uma perspectiva descritiva que permite situar as práticas criminosas nas suas relações com o que poderíamos definir como gestão das ilegalidades inscritas nos agenciamentos concretos da vida cotidiana. A rigor, esse é foco da discussão que se pretende aqui desenvolver; quer dizer: não tanto o tráfico de drogas em si mesmo, mas essa crescente e ampliada zona de indiferenciação entre o legal e o ilegal, o lícito e o ilícito, e que se processa nas relações redefinidas entre o informal, o ilegal e o ilícito.

Se é verdade que o mundo urbano - o "bazar metropolitano" em suas modulações locais - é atravessado pelas forças estruturantes que redefinem as relações do trabalho e não-trabalho, entre o formal e o informal, o legal e o ilegal, esses processos operam em situações de tempo e espaço. Processos situados, portanto. E agenciados por meio de mediações e conexões de natureza e extensão variada. Por isso mesmo, só podem ser compreendidos nessas constelações situadas (cf. Telles, 2007, p.207-8). E é isso propriamente que exige uma estratégia descritiva. De nossa parte, e esse é o nosso pressuposto teórico-metodológico, optamos pelo exercício de uma "etnografia experimental”, tomando como referência "cenas descritivas" que permitam flagrar as novas mediações e conexões pelas quais vêm se processando esses deslocamentos às fronteiras do legal e ilegal. Não se trata de partir de objetos ou "entidades sociais" tal como se convencionou definir de acordo com os protocolos científicos das ciências sociais, mas sim de situações e configurações sociais a serem tomadas como cenas descritivas que permitam seguir o traçado dessa constelação de processos e práticas, suas mediações e conexões pelas quais as ilegalidades (novas e velhas) vêm sendo urdidas nas tramas urbanas.

Com base em pesquisa recente (e ainda em curso), tomamos como ponto de partida - o nosso primeiro "posto de observação" - uma cena urbana armada em torno de expedientes corriqueiros de sobrevivência em um bairro periférico da cidade de São Paulo, pondo em foco suas mediações e conexões e, a partir daí, seguindo os percursos de um pequeno traficante local, os perfis urbanos que, nesses percursos, vão se desenhando nas fronteiras porosas entre o legal e o ilegal, e o ilícito. 
Cena corriqueira na periferia paulista. Um ponto distante da cidade de São Paulo, um bairro feito de irregularidades várias e superpostas. Ocupações e terrenos de propriedade incerta. Tudo muito improvisado e tudo muito precário, moradias erguidas aqui e ali conforme chegaram os moradores, espalhando-se no traçado de ruas esburacadas, sem pavimentação e que se transformam em verdadeiros lodaçais nos dias de chuva. Mas as redes de água e luz, finalmente, chegaram a esses confins da cidade. A expansão das redes urbanas aconteceu nas últimas décadas. Porém, no mesmo passo e no mesmo ritmo, multiplicaram-se as ligações clandestinas. Junto com o "progresso urbano", o reinado das gambiarras também se espalhou por todos os lados. Nada muito diferente do que acontece desde muito tempo, compondo o que foi convencionado discutir nos termos do descompasso entre a cidade legal e a cidade real.

Nada muito diferente, não fosse o modo como esse peculiar artefato urbano vem sendo produzido e agenciado nos últimos tempos. Na verdade, é a cidade ou as linhas de força de sua atualidade, que pulsam nesse artefato urbano (e outros). E são essas linhas de força que se entrelaçam e se compõem nos agenciamentos práticos da vida cotidiana: conexões e mediações da vida urbana que ficariam fora de mira se insistíssemos, como é comum nos chamados estudos da pobreza urbana, na ficção de populações encapsuladas em suas "comunidades" ou encerradas no circuito estreito de redes sociais supostamente (apenas) locais.

Estacionado ali perto, um carro de uma empresa que faz o serviço de manutenção de uma grande companhia telefônica. Afinal, a rede de telefonia também chegou aos pontos mais distantes da cidade. Proezas da privatização, é o que se diz. O técnico conversa com um dos moradores do local. É ele quem vai fazer o serviço. Quer dizer: puxar os fios da avenida principal e, de quebra, garantir luz e telefone para todos. É um empregado terceirizado de uma empresa privatizada. Não tem estabilidade no emprego e é muito mal remunerado: enfim, é um trabalhador precário. Como tantos outros, não deixa escapar a oportunidade de complementar seus parcos rendimentos, com a peculiaridade de que, agora, os próprios dispositivos de um serviço terceirizado abrem as passagens entre o formal e o informal, entre o legal e o ilegal, e o tradicional bico se faz justamente nas dobraduras entre uns e outros.

Enfim, é a nossa velha conhecida viração popular, mas que ganha, agora, outras mediações, já que conectada nos circuitos da face moderna-moderníssima da vida urbana. Coisa, aliás, que também acontece do outro lado. Pois a prestação do serviço tem suas formas de regulação. Tudo tem que ser bem negociado. A começar do preço e dos custos a serem partilhados por todos. Além disso, há que se acordar sobre o traçado dos fios, as casas que serão beneficiadas, a extensão da rede clandestina, por onde passar e por onde se ramificar. Quer dizer: há todo um delicado agenciamento da vida local, e é isso o que está no foco das conversações.

O morador é um rapaz com os seus 28 anos, que mora lá com mulher, filhos e mais a mãe, irmãos e sobrinhos. Ele conduz as negociações com habili- 
dade. Ninguém sabe ao certo o que ele faz e, se sabe, faz que não sabe. Mas isso não tem lá muita importância sob o ângulo da sempre difícil gestão cotidiana de vidas que se estruturam no fio da navalha de precariedades várias e superpostas. E o que importa é que o rapaz é um moço respeitador e gentil com todos, com uma família muito bem estruturada, uma filhinha adorável e uma esposa prestativa, sempre disposta a ajudar quem quer que esteja passando por algum aperto. Pois o rapaz ganha a vida traficando drogas. Ele é o "patrão" de uma "biqueira" bastante movimentada. Não lá onde mora. Mas em um bairro das imediações, aliás o lugar onde nasceu, cresceu, casou e constituiu família, até que, por uma dessas piruetas do destino (briga de família e vizinhos, que resultou em história de sangue), as suas perspectivas de trabalhador (sim, ele era um trabalhador no mercado formal e com carreira promissora) viraram fumaça e ele se viu enredado nas tramas da chamada economia dos bens ilícitos.

Ele, no entanto, não mistura seus negócios com a vida privada. No bairro em que mora, leva a vida de "todo o mundo". Mas, se é ele quem comanda essa espécie de gestão das múltiplas ilegalidades de que é feito o mundo urbano, é porque sabe lançar mão dos ardis de uma inteligência prática que combina senso de oportunidade e a arte do contornamento das situações difíceis. ${ }^{2}$ Nas quebradas da vida, desenvolveu uma especial habilidade em negociar a vida nas dobraduras do legal e ilegal e se equilibrar no frágil equilíbrio de que é feito os negócios ilícitos: de partida, o pesado jogo entre a compra de proteção e a extorsão policial, na verdade um feroz jogo de poder que se faz nas fronteiras porosas entre o legal e o ilegal, e o ilícito - é disso que depende o funcionamento do negócio, dessa espécie de dobradura entre os dois lados, e que aciona séries seguidas de violência, episódios corriqueiros que, muito freqüentemente, ganham formas extremadas e devastadoras (cf. Misse, 2006b), de um lado; de outro (e ao mesmo tempo), a gestão das rotinas do seu negócio, que se conectam com as circunstâncias da sociabilidade local, entre o respeito às regras da reciprocidade da vida cotidiana (afinal, foi lá que nasceu e cresceu, construiu laços de amizade e solidariedade), o cálculo refletido para garantir a cumplicidade dos moradores contra as investidas da polícia e também estratégia para controle de território ante os grupos rivais e sempre em disputa.

Aqui, nesse bairro, outras tantas histórias poderiam ser contadas, miríades delas, microcenas de um mundo feito da superposição e entrelaçamento de múltiplas ilegalidades. Ou melhor: um mundo social feito de um especial embaralhamento entre o formal e o informal, o legal e ilegal, e o lícito. Daí o interesse em se deter nos expedientes mobilizados em torno de uma muito prosaica gambiarra, esse peculiar artefato que carrega diversos estratos da história urbana, que se comunicam e se entrelaçam nos agenciamentos práticos da vida cotidiana.

Aliás, os mesmos procedimentos e os mesmos mediadores postos em ação para puxar a luz para uma pequena-pequeníssima favela que rapidamente se formou lá mesmo no bairro em que o rapaz capitaneia o seu negócio. Esse é um bairro mais antigo, com uma urbanização consolidada faz tempo. Porém, em 
um terreno vazio apareceram os primeiros moradores que, sem outras opções, lá instalaram casa e família para tocar suas vidas. A favela estava ali se formando aos olhos de todos. Tudo bem, tudo certo, nada muito diferente do que todos conhecem, e conhecem de longa data, até porque, em suas origens, nos idos dos anos 1970, esse bairro também foi uma área de ocupação ilegal de terras. Mas acontece que apareceram uns e outros, também moradores da região, que atuavam como uma espécie de grileiro popular, apossando-se de um terreno para, depois, alugar ou vender o ponto para os recém-chegados. O rapaz e seus parceiros (aliás, todos eles moradores antigos do pedaço) ponderaram que era preciso garantir que as coisas funcionassem, como se diz (eles dizem), "pelo certo". Expulsaram esses mercadores da desgraça alheia, dividiram os lotes direitinho e estabeleceram as regras para a sua distribuição entre os que, de fato, deles precisavam. Depois, trataram de garantir os “serviços urbanos”, de luz e água, lançando mão, claro está, dos serviços profissionais de quem entende do assunto e é capaz de fazer bem o serviço - e lá estão as gambiarras de luz e as ligações clandestinas de água, tudo funcionando direito para o bem-estar de todos...

O fato é que o rapaz e seus parceiros passaram, aos poucos, a se ocupar dos assuntos locais. Foi assim também com a cesta básica, um outro artefato urbano em torno do qual relações sociais são tecidas, conexões são urdidas e redes sociais são mobilizadas. Em torno desse artefato, outros tantos coletivos são mobilizados. ${ }^{3}$ Antes de mais nada, claro está, as famílias pauperizadas cujas vidas parecem como que dependuradas nos programas sociais, sem outros meios de sobrevivência: problemas de saúde, de desemprego, de orfandade, de abandono; também a prisão de provedores, pais ou filhos, ou então a morte violenta dos que foram atingidos por um desses "mata-mata", como se diz, episódios recorrentes que fazem parte da história local (não só local) e que não são de hoje, vêm de longe, em que se misturam a violência policial (e as práticas de extermínio), a ação de matadores e justiceiros, disputas de territórios e acertos de conta.

Desde muito tempo, as cestas básicas são distribuídas por uma tradicionalíssima liderança comunitária. Moradora das mais antigas do bairro, desde cedo se empenhou nesse empreendimento solidário. E desde cedo e por anos seguidos, não poupou esforços para solicitar a ajuda de todos quantos pudessem mobilizar recursos, quer dizer: doações voluntárias (e incertas) dos comerciantes locais, prestação (além de incerta, descontínua) de associações filantrópicas e também, e sobretudo, o clientelismo político velho de guerra, e, nesse caso, as doações seguiam os rumos mutantes dos interesses políticos e o ritmo descompassado do calendário eleitoral.

Mais recentemente, nos últimos cinco ou seis anos, quando o rapaz e seus parceiros entraram na parada, outras redes e outras mediações foram mobilizadas: comerciantes e perueiros, eles próprios atuando nessas zonas de incertezas entre o informal e o ilegal, sempre às voltas com as "forças da ordem" (fiscais e policiais) pelas vias da chantagem e extorsão, além dos assaltos e roubos da pequena delinqüência local e, no caso dos perueiros, disputas, por vezes le- 
tais, envolvendo grupos rivais pelo controle dos rendosos circuitos do chamado transporte alternativo. Em troca da proteção, semi-solicitada, semi-imposta, entraram todos no circuito da solidariedade popular, garantindo os recursos e também a fachada semilegal para as cestas básicas que continuaram a ser distribuídas e geridas como sempre foram, desde o começo.

Na verdade, uma muito modesta e tradicional cesta básica opera aqui como um desses pontos de entrelaçamento de redes que operam em escalas e conexões variadas. Famílias pauperizadas, liderança comunitária, traficantes locais, comerciantes e perueiros são moradores que partilham a história comum de um mesmo bairro, conhecem as venturas e desventuras de uns e outros. Cada qual e, sob maneiras diversas, transita entre um lado e outro, nas fronteiras incertas do legal, do informal e ilícito: famílias cujos filhos estão presos ou foram mortos em algum desses trânsitos entre o legal e o ilegal; o traficante que já foi um trabalhador no mercado formal de trabalho, um outro que intercala expedientes vários no mercado informal e o negócio da droga ou que tenta consolidar uma pequena loja nas imediações com a expectativa (ou o sonho) de, um dia, sair da vida do crime; o perueiro que já traficou drogas em outro momento e

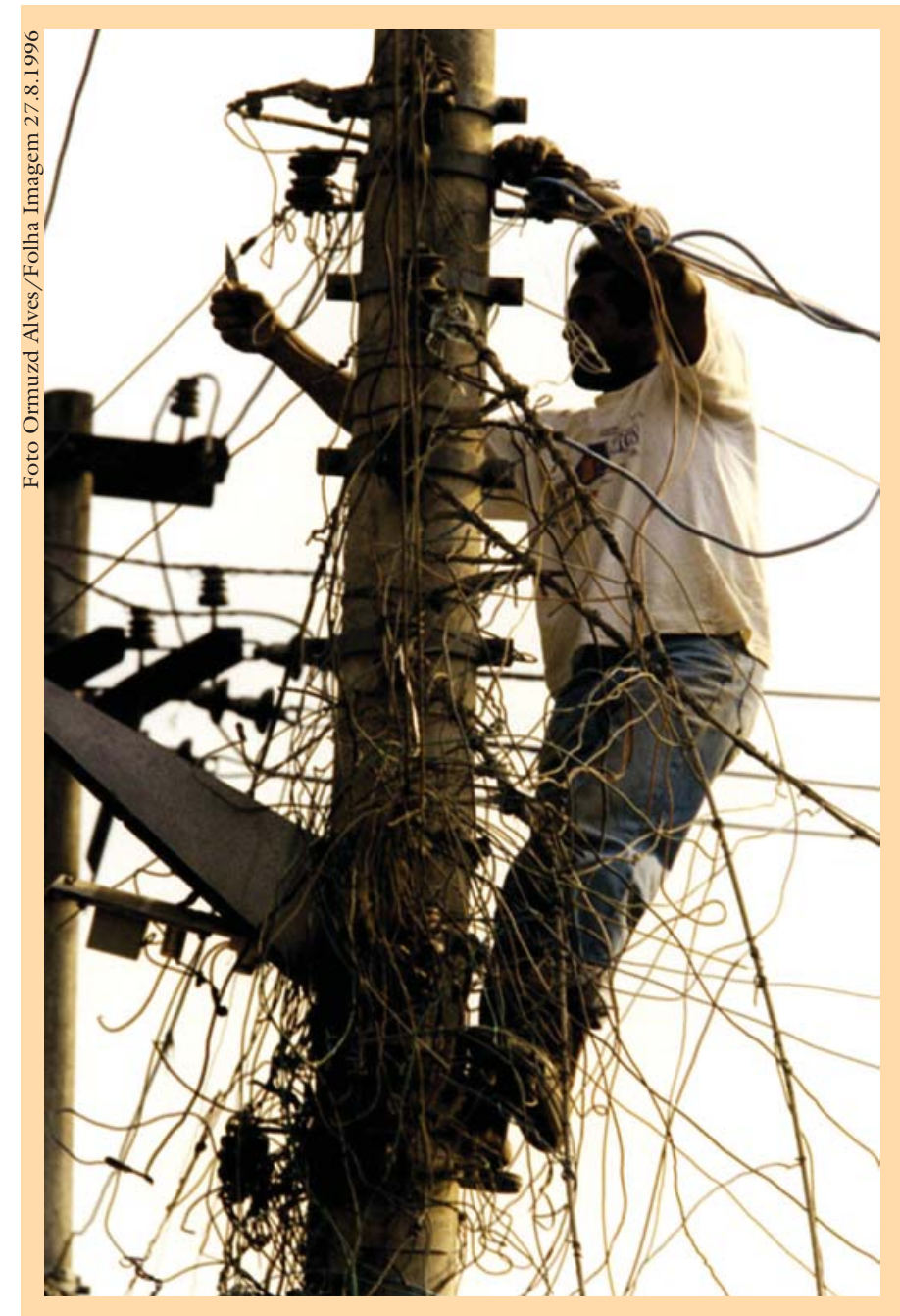

Em 24 municípios da Região Metropolitana de São Paulo, cerca de 300 mil gambiarras garantem luz para um milhão de pessoas, segundo estimativas da concessionária Eletropaulo. resolveu dar um novo rumo para sua vida (ou o contrário); o comerciante cujo filho é perueiro e sabe das complicações que acompanham seus trajetos na cidade; a liderança comunitária, que já foi uma aguerrida militante dos outrora ativos movimentos de moradia, que nos períodos de eleição se converte em um 
muito eficaz cabo eleitoral de vereadores locais, que tem um filho perueiro e uma filha viúva de um rapaz executado pela polícia por razões obscuras, que ganhou respeito e admiração não apenas pelo seu empenho solidário, mas também pela ousadia com que, ao longo dos anos e por vezes seguidas, se interpôs, fisicamente e com ameaças de denúncia pública, entre a polícia e aquele que, qualquer que fosse a razão, estava ali sendo alvo de violência, ameaça de extermínio ou prisão arbitrária.

Poderíamos seguir, sem fim, esse jogo em que os personagens urbanos transitam, interpõem, deslocam, trocam, comutam entre esses vários "lugares" sociais: esse é propriamente o circuito que podemos reconstituir em torno de uma cesta básica, circuito que, a cada um de seus pontos, desenha os perfis de um mundo social no qual transitam "histórias minúsculas", delineando, cada qual, as modulações desse estado de exceção permanente cifrado em cada uma delas e constelado nos agenciamentos práticos da vida cotidiana.

Mas, então, continuemos. A distribuição das cestas básicas segue suas rotinas. O “patrão" do negócio local é agora o seu fiador, e garante que tudo siga no rumo certo das coisas. E assim também acontece com os festejos que ele trata de patrocinar e organizar nas datas comemorativas: dia das mães, dia das crianças, Natal e fim de ano. No mês de junho, o campo do futebol de várzea se transforma em espaço para as festas juninas. Outros tantos agenciamentos locais: o rapaz e seus funcionários mais graúdos negociam com os times locais o uso do espaço, conversam com o pessoal do Centro Desportivo Municipal (mediação oficial e legal, que gerencia o espaço, os jogos e times locais), patrocinam a montagem e organização das barracas utilizadas pelos moradores para vender as comidas e bebidas próprias de uma festa junina. E, ainda por cima, garantem que tudo seja bem iluminado por gambiarras espalhadas em pontos estratégicos - de novo elas, e sempre pelas mesmas vias.

A festa é um sucesso de público e crítica. Tão grande foi o sucesso da primeira iniciativa, que resolveram prolongar a festa por três meses, todos os fins de semana. Parentes, conhecidos, vizinhos, casais de namorados circulam alegremente por lá. As crianças se divertem com o pau de sebo. E as famílias celebram essa, digamos assim, variação local da economia solidária, pois as barracas se mostraram uma nada desprezível fonte de renda para quem está sempre às voltas com salários irrisórios, empregos incertos e desemprego prolongado. Como se vê, tudo muito bem sintonizado com os tempos atuais.

Com o tempo, o rapaz tornou-se um personagem importante na vida local. Não poucas vezes, ao andar pelas ruas, é chamado, com um evidente senso de ironia, de prefeito. Alguns pedem emprego, dinheiro, carro para levar um familiar doente para o hospital, favores em geral. Na prática, ele atua com um agenciador de problemas cotidianos: brigas de vizinhos, conflitos de família, adolescentes briguentos e desabusados, barulho excessivo nas altas horas da noite. Quer dizer: tudo e qualquer coisa que possa chamar a atenção da polícia ou 
que possa provocar a hostilidade e má vontade de moradores, situação delicada e perigosa, pois é sempre assim que surgem as temidas denúncias anônimas que acionam a intervenção violenta da polícia.

$\mathrm{Na}$ verdade, a biqueira funciona ali como uma espécie de caixa de ressonância de tudo o que acontece no bairro: as informações ou rumores circulam por ali, e o patrão e seus "gerentes" conversam, discutem, ponderam e decidem como intervir e arbitrar conflitos corriqueiros e situações difíceis. Ou então, para garantir, como se diz (eles dizem), o "lado certo da coisa errada" quando as situações são provocadas por gente envolvida nos negócios do crime.

O fato é que tudo isso se confunde com a gestão cotidiana do negócio local da droga, que depende em boa medida de seu ancoramento nessas redes de sociabilidade. Ao mesmo tempo, a biqueira engendra outras tantas relações no bairro, elas próprias se estruturando em equilíbrios instáveis e sempre passíveis de desandar em tensões, conflitos, desafetos, desentendimentos, deslealdades, disputas ou histórias de vingança pessoal, que podem ser fatais - e letais, para uns e outros, ou para todos. É todo um agenciamento das relações locais também mobilizado para garantir a lealdade dos "funcionários" e a cumplicidade de suas famílias, para arbitrar conflitos que muitas vezes se confundem com desentendimentos pessoais ou desacertos de outros tempos e outros lugares; ou então para definir os limites que não devem ser ultrapassados, sobretudo para os mais jovens, na verdade garotos, quase crianças, quando passam a se achar importantes e poderosos, e criam problemas com os moradores e a vizinhança.

Equilíbrios instáveis, até porque se estruturam entre essa dinâmica local e os igualmente instáveis acordos com a polícia: a rotina do pagamento "regular" da proteção muito freqüentemente desanda na prática aberta da chantagem e extorsão, e isso concerne direta e abertamente essa teia de relações que passam pelas conexões do negócio com a vida local: espancamento e chantagem sobre uns, ameaça de prisão de outros, verdadeiros seqüestros, muito freqüentemente, com a exigência de um alto preço pelo "resgate". No alvo, estão os "meninos da droga".

Mas não só. Qualquer um que, nesse trânsito nas fronteiras embaçadas do legal e ilegal, possa oferecer algum pretexto para a pressão, chantagem e ameaça de prisão: pequenas histórias locais, "histórias minúsculas" ou "histórias infames", que passam por delitos menores ou passagens esporádicas pelo ilícito, casos mal resolvidos de outrora ou ainda desavenças pessoais, histórias que circulam e povoam a vida local, que se misturam com a "vida-de-todo-o-dia" e que são acionadas nesses pontos de fricção da vida local e que, de alguma forma, se condensam no varejo da droga, nas várias dimensões de suas regulações locais.

O fato é que essa gestão das relações cotidianas tangencia outras tantas práticas ilícitas, que nem sempre e não necessariamente têm comprometimentos com o negócio da droga, mas que também interagem com as redes da sociabilidade local nas fronteiras incertas entre o informal e o ilegal: as tradicionalíssimas 


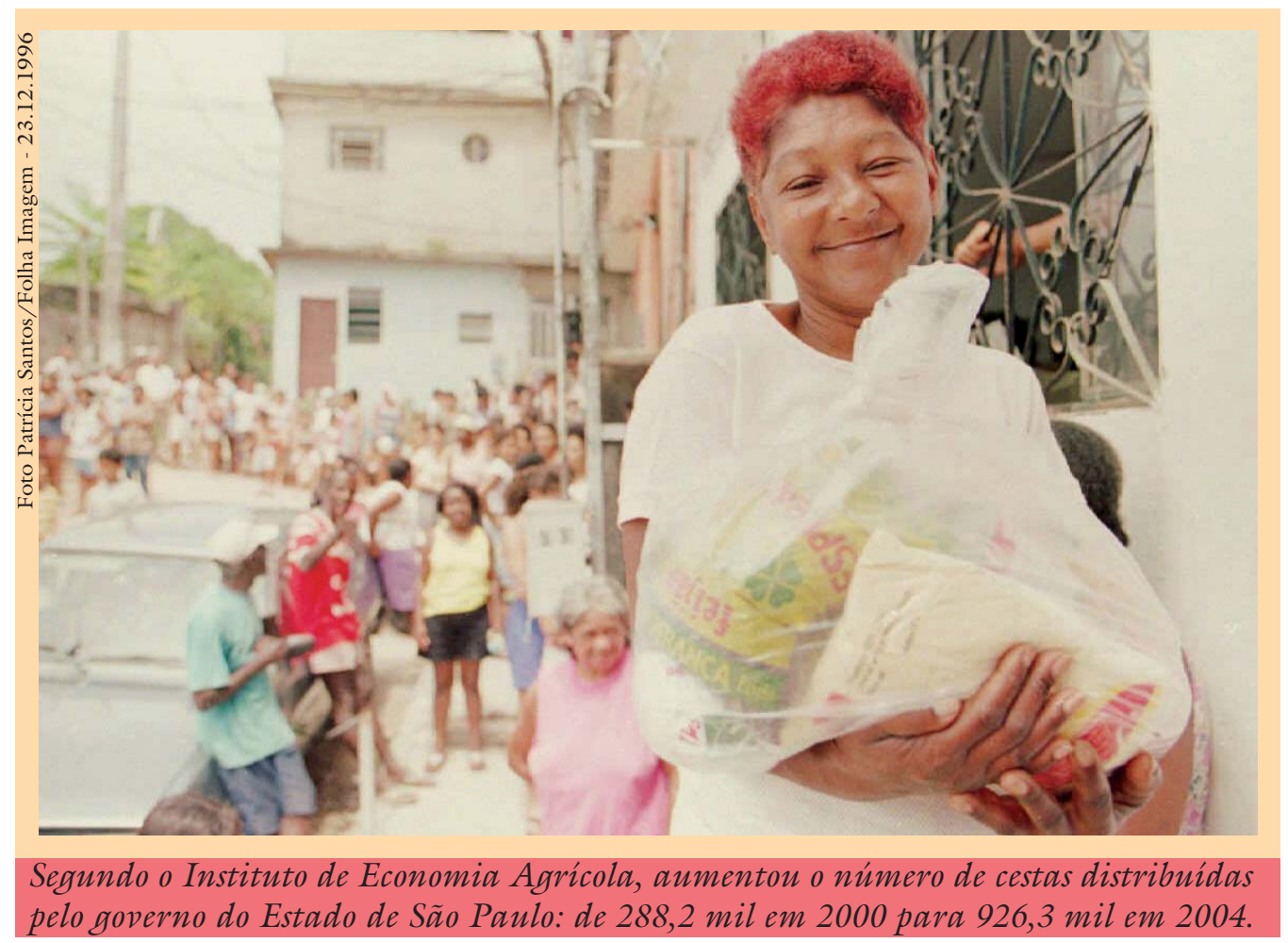

oficinas de carro, que se multiplicam por toda a periferia, em que se misturam o trabalho informal e a transação de peças de origem duvidosa, em conexão (ou não) com os vários pontos de desmanche de carros roubados, tudo isso alimentando um espantoso mercado popular de peças, motos e automóveis de "segunda mão"; os muito modernos mercados de CD pirata, produtos falsificados ou então contrabandeados (dos cigarros vindos do Paraguai, passando por isqueiros vindos sabe lá de onde, até os eletrônicos que chegam dos contêineres chineses desembarcados no porto de Santos), fontes de renda para os que agenciam os pontos de venda pelas periferias afora, mobilizando redes locais de sociabilidade e mais uma cascata confusa de intermediários por onde esses produtos circulam nos hoje expansivos mercados de consumo popular; ou então o atualíssimo e muito rendoso negócio com caça-níqueis que vem ocupando o lugar do tradicional jogo do bicho, e que, como esse, também opera no jogo de luz e sombra entre intermediários obscuros, a compra de proteção policial e os rendimentos generosos para os que alojam e operam essa versão moderna do jogo de azar hoje comum em qualquer birosca de um bairro de periferia. ${ }^{4}$

Práticas comuns, em suas versões tradicionais ou muito modernas, que transitam nas fronteiras borradas entre expedientes de sobrevivência e práticas ilícitas (Ruggiero, 2000). Podem estar vinculadas (ou não, e não necessariamente) à pequena criminalidade local ou às redes mobilizadas por esquemas mais pesados, como é o caso do roubo de carga. Ou então, estão articuladas, aliás, como o próprio varejo da droga, nas pontas pobres dos hoje expansivos e 
rendosos circuitos ilegais de uma economia globalizada (cf. Naim, 2006). São práticas e redes sociais que atravessam e compõem a vida de um bairro de periferia. E criam outras tantas zonas de fricção que, também elas, precisam ser bem agenciadas para evitar complicações com a população local e, sobretudo, evitar ocorrências indesejáveis com a polícia.

Aqui, o outro plano em que se dá a regulação dos negócios locais: a gestão das várias ilegalidades e práticas criminosas que perpassam o mundo urbano, que transbordam, certamente, o perímetro local, mas que se entrelaçam nas pontas pobres do varejo da droga e fazem de uma pequena biqueira o ponto sensível de suas operações justamente nas suas conexões com as circunstâncias locais, entre as regras da sociabilidade vicinal, os sempre instáveis acordos com a polícia, e também a nem sempre pacífica relação com organizações criminosas: acertos sobre procedimentos, horas, lugares e circunstâncias para as transações ilícitas ou, então, acordos de conveniência para impedir disputas indesejáveis entre grupos que atuam em territórios contíguos. Também: arbitragens difíceis quando as desavenças envolvem organizações criminosas, e a situação beira soluções de morte.

O que está em jogo

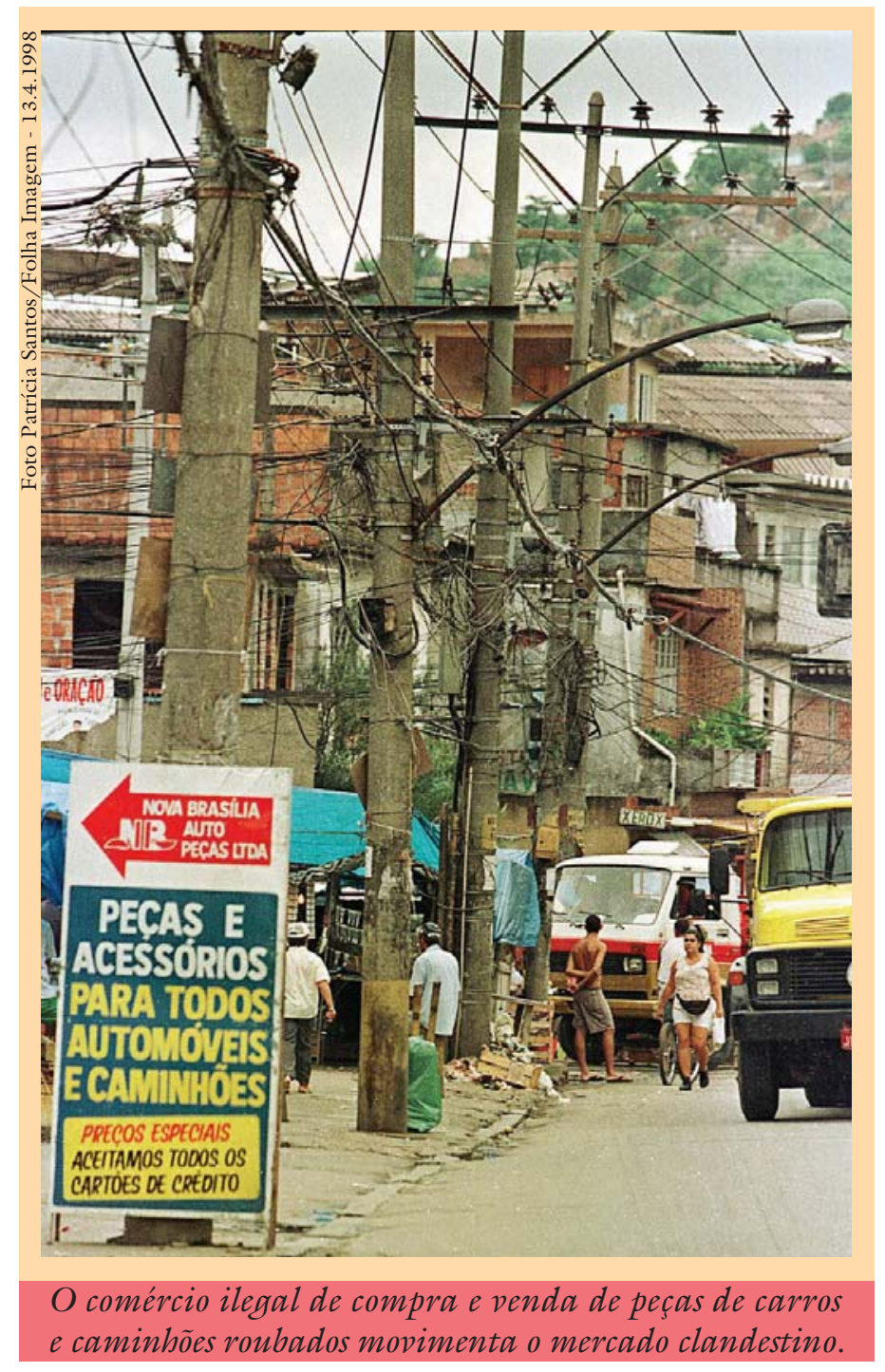
nisso tudo são microrregulações do negócio da droga, a sua face miúda, poderíamos dizer, que se conecta com os fatos e circunstâncias, artefatos e redes sociais que compõem a vida local. Disso depende o bom andamento dos negócios. Mas é disso que dependem, sobretudo, as partidas de um arriscado jogo de vida e morte. Pois tudo funciona muito bem, ou pode funcionar até o momento em 
que a roda da fortuna dá mais um giro e os desacertos da vida jogam tudo pelos ares, sejam os desacertos com a polícia que está sempre lá em um jogo perverso de proteção e extorsão, seja por conta de disputas de território com os grupos rivais, seja pelos desafetos de uns e outros e que terminam por acionar soluções de morte. O rapaz sabe disso, ele e todos os outros, os moradores também.

Histórias de um pequeno traficante da periferia paulista. Histórias minúsculas, como diria Foucault (2003), essas "existências destinadas a passar sem deixar rastro", mas que interessam justamente porque, ao contrário das estereotipias que constroem as figuras fantasmáticas do Traficante e do Crime Organizado, são portadores de um feixe variado de relações e conexões com o mundo social. Por isso mesmo são formidáveis guias para nos conduzir nessa incerta prospecção do mundo urbano atual.

São histórias que se fazem nas dobraduras do mundo social, nesses pontos de junção e conjugação da trama urbana nas fronteiras incertas entre o informal, o ilegal e o ilícito. Nelas pulsam as linhas de força que atravessam o cenário contemporâneo, e que parecem se entrelaçar e se compor nos diversos agenciamentos práticos da vida cotidiana: práticas e redes sociais mobilizadas nesse trânsito constante entre um lado e outro, acionando recursos, possibilidades e dispositivos de cada lado. É isso o que interessa colocar em foco. E foi por isso que começamos com uma muito prosaica gambiarra, para seguir, depois, os agenciamentos mobilizados em torno de uma inofensiva cesta básica e de uma popular festa junina. É isso que pode fornecer um plano de referência para situar os percursos de um pequeno traficante local e, por meio deles, desses percursos, delinear os perfis de uma cidade que ainda resta a conhecer.

Tudo muito distante das imagens hoje amplamente midiatizadas - e aceitas como fato e verdade - de um mundo capturado e dominado pelo assim chamado "Crime Organizado". Imagens que banalizam a criminalização da pobreza e alimentam a obsessão securitária que combina repressão aberta e sem pudor (a gramática da guerra, combate ao "inimigo") e a gestão dos supostos riscos da pobreza ${ }^{5}$ pelas vias de dispositivos gestionários voltados às ditas "populações em situação de risco" (expressão hoje moeda corrente, e não por acaso), a rigor, o biopoder de que fala Foucault (2004); quer dizer: gestão das populações, gestão das vidas e, nesses tempos em que a exceção se tornou a regra, a administração de suas urgências para tornar os "indivíduos governáveis" sob a égide da racionalidade triunfante do mercado.

Talvez aqui fique mais claro por que escolhemos esse sinuoso percurso pelas "histórias minúsculas" para colocar a cidade em perspectiva e sob outra perspectiva. Exigência, para nós imperativa, de deslocar o terreno a partir do qual descrever a ordem das coisas, e problematizar as questões em pauta. Deslocar o ponto da crítica. Ou melhor: ajustar o ponto da crítica que, hoje, parece ter se esvaecido na própria medida em que se esvazia a imaginação política que 
não consegue figurar o mundo a não ser nos termos postos no presente imediato. Se essas microcenas interessam é porque colocam em foco um mundo social que não cabe nas estereotipias que vêm acionando os dispositivos de exceção: sejam as figuras fantasmáticas do Crime Organizado, suposto poder paralelo, versão nativa do "império do mal" contra o qual só resta a estratégia da guerra (e extermínio) seja, na sua face "edificante", a ficção de populações encapsuladas nas ditas "comunidades" (aliás, termo sobre o qual valeria se deter em outro momento), subjugadas ou aterrorizadas, no mínimo ameaçadas, mas destinadas à remissão pela intervenção salvadora de programas sociais.

Em nome da urgência e da emergência, o espaço da política é subtraído, tanto quanto é erodido o campo da crítica e o exercício da inteligência crítica (cf. Calhoun, 2004) sob a figuração de uma cidade toda ela pensada e figurada sob a lógica de uma gestão dos riscos, riscos sociais, pautando programas sociais e também os hoje celebrados projetos de revalorização de espaços urbanos, populares ou centrais, ${ }^{6}$ indicações que nos fazem pensar já estar em operação novas formas de controle que, como diz Garland (1999 e 2001), combinam a lógica punitiva e a governamentalização das populações e situações sujeitas ao que passa a ser definido como risco do crime e da violência.

Com isso, é todo um mundo social que fica fora de mira. Mas é aqui que se alojam as complicações, justamente nessas tramas urbanas feitas nas dobraduras do formal e informal, do legal e ilegal. É nelas, nessas dobraduras, que é preciso se deter. Como mostra Michel Misse (2006b), a chave para o entendimento da violência associada aos mercados ilícitos, em particular o tráfico de drogas, está justamente aí, nas "ligações perigosas", relações de poder articuladas no pesado jogo da compra de proteção e extorsão policial, o chamado mercado de proteção, ele também ilegal, que se alimenta das políticas (e práticas) da criminalização, parasita os primeiros e detona episódios contínuos de violência que, muito freqüentemente, assumem formas extremadas e devastadoras.

Os dispositivos de exceção, no entanto, nas suas duas faces, a repressão e a gestão da pobreza, já compõem a ordem das coisas. Seria mesmo possível dizer que as tensões do mundo se fazem na fricção entre os "indivíduos governáveis" (Foucault, 2004) e o que escapa dos dispositivos gestionários, quer dizer: entre a governabilidade gestionária e a "vida nua” (Agamben, 2002). É isso o que pulsa, em filigrana, nos agenciamentos práticos da vida cotidiana. É nesses pontos de fricção que homens e mulheres negociam a vida e os sentidos da vida. No fio da navalha. O fato é que indivíduos e suas famílias transitam nessas tênues fronteiras do legal e legal, ${ }^{7}$ sabem muito bem lidar com os códigos de ambos os lados e sabem também ou sobretudo lidar com as regras que vão sendo construídas para "sobreviver na adversidade". Essa expressão, "sobreviver na adversidade", não tem nada a ver com as estratégias de sobrevivência de que tratam os estudos sobre pobreza. ${ }^{8}$ É uma expressão que circula no "mundo bandido". Mas os moradores das periferias da cidade sabem muito bem o que isso quer dizer: saber transitar entre fronteiras diversas, se deter quando é preciso, avançar quando é 
possível, fazer o bom uso da palavra certa no momento certo, se calar quando é o caso.

Não se trata tão simplesmente de sobreviver e levar a vida. Trata-se, sobretudo, de contornar - é uma espécie de arte de contornamento ${ }^{9}$ - as duas ameaças muito concretas que se colocam em suas vidas, a cada momento. De um lado, o risco da morte violenta: sobretudo entre os mais jovens, fazer a narração de suas vidas é também uma espécie de contabilidade dos mortos, pessoas próximas, amigos de infância, vizinhos de rua, colegas de escola. De outro, o risco de despencar na condição de "pobres-de-tudo", a depender da caridade de uns e outros, público-alvo dos programas sociais ditos de inserção e que, nas palavras de Chico de Oliveira (2003), não são mais do que a administração da exceção.

Quer dizer: entre a morte-matada e a pobreza cativa dos dispositivos gestionários não há o vazio sugerido pelas noções correntes de exclusão social. Há todo um mundo social tecido nesses terrenos incertos nas fronteiras porosas do legal e ilegal, do lícito e ilícito, e por onde transitam as "histórias minúsculas" de que é composta a vida urbana. É aí que se joga a partida entre a vida nua: quer dizer: a vida matável; e as formas de vida, quer dizer: possibilidades e potências da vida. Acolhendo a sugestão de Agamben (2002), é isso o que ainda precisa ser bem entendido se quisermos pensar uma política que esteja à altura desses tempos em que a exceção se transformou em regra.

\section{Notas}

1 A redefinição das relações entre o formal e o informal no capitalismo contemporâneo e, mais particularmente, o lugar redefinido do informal, sob a lógica de um processo de acumulação que exige, mobiliza e aciona a sua reprodução ampliada está hoje no centro de um debate que já conta com uma importante literatura de referência. Para as questões aqui discutidas, além de Ruggiero (2000) já citado, ver Sassen (1989) e Portes \& Castells (1989).

2 Para uma discussão sobre os sentidos dessa inteligência prática em contextos nos quais as regras são incertas e mutantes, e as realidades são indeterminadas e ambíguas, ver Detienne \& Vernant (1974).

3 Estamos aqui trabalhando com a noção de "artefato", tal como sugerida por Bruno Latour (2000), ponto de partida para a descrição de práticas, relações e mediações acionadas em seus agenciamentos.

4 A imprensa tem noticiado o importante lugar do comércio de máquinas de caça-níqueis nas operações de lavagem de dinheiro capitaneadas por redes transnacionais, das quais, como se pode supor, os modestos donos de birosca nas periferias não suspeitam nem poderiam imaginá-las. Cf. Carta Capital, 24.3.2007, n.441, "Conexão Parque Lage", reportagem de Walter Fanganiello Maierovich.

5 No momento em que estas linhas estão sendo escritas, estamos testemunhando ao vivo e em ato os modos como esses, o leitor nos perdoe o eufemismo, dispositivos de exceção, estão sendo, mais uma vez, colocados em prática na ocupação do Complexo do Alemão no Rio de Janeiro, cidade hoje escolhida, assim parece, como um laboratório 
para calibrar a versão nativa de uma mistura do dito Modelo Colômbia e Modelo Haiti. Cf. Carta Capital, 13.6.2007, "Dentro das regras: exército nas ruas", reportagem de Mauricio Dias.

6 Nisso, ao que parece, estamos também em fina sintonia com a modernidade neoliberal em tempos de exceção, a se considerar o que Vincenzo Ruggiero (2007) descreve do que anda acontecendo na cidade de Londres.

7 No que segue, retomamos questões desenvolvidas em Telles (2007).

8 Os usos e sentidos dessa expressão, "sobreviver na adversidade", é questão trabalhada e desenvolvida em Hirata (2006).

9 Sobre essa "arte do contornamento", ver Fresia (2004): em seu estudo sobre os inusitados percursos de jovens refugiados nas fronteiras do Senegal e da Mauritânia, a autora levanta questões que têm paralelos interessantíssimos com o que está aqui sendo proposto.

Referências bibliográficas

AGAMBEN, G. Homo Sacer. O poder soberano e a vida nua. Belo Horizonte: Editora UFMG, 2002.

BAYART, J.-F. Le crime transnational et la formation de l'État. Politique Africaine, Paris, n.93, p.93-194, mars 2004.

BOTTE, R. Vers un État illégal-légal? Politique Africaine, Paris, n.93, p.7-21, mars 2004.

BOURGOIS, P. In search of respect. Cambridge: Cambridge University Press, 1995.

CALHOUN, C. A world of emergencies: fear, intervention, and the limits of cosmopolitan order. The Canadian Review of Sociology and Anthropology, v.41, Nov. 2004.

DETIENNE, M.; VERNANT, J.-P. Les ruses de l'inteligence. Le métis des Grecs. Paris: Flammarion, 1974.

FRESIA, M. “Frauder” lorsqu'on est refugié. Politique Africaine, Paris, n.93, p.63-81, mars 2004.

FOUCAULT, M. A vida dos homens infames. In: . Ditos \& escritos IV. Rio de Janeiro: Forense Universitária, 2003.

Naissance de la biopolitique. Paris: Gallimard, 2004.

GARLAND, D. As contradições da "sociedade punitiva": o caso britânico. Revista de Sociologia e Politica, Curitiba, n.13, p.59-80, nov. 1999.

The culture of control. Oxford: Oxford University Press, 2001.

HIRATA, D. No meio do campo: o que está em jogo no futebol de várzea. In: TELLES, V.S.; CABANES, R. Nas tramas da cidade. Trajetórias urbanas e seus territórios. São Paulo: Humanitas, 2006. p.243-90.

KOKOREFF, M. Trafics de drogue et criminaliteé organisée: une relation complexe. Criminologie, Paris, v.7, n.1, 2004.

Mythes et réalités des économies souterraines dans le monde des banlieues populaires françaises. In: KOKOREFF, M. et al. (Ed.) Economies criminelles et mondes urbains. Paris: PUF, 2007. p.74-86. 
KOKOREFF, M. et al. Economies crimminelless et monde urbain. Paris: PUF, 2007.

LATOUR, B. Faktura. De la notion de réseaux à celle d'attachement. In: MICOUD, A.; PERONI, M. Ce qui nous relie. Paris: Éditions de l'Aube, La Tour d'Aigues, 2000. p.189-208. Também disponível em: <www.ensmp.fr/ latour>.

MISSE, M. O Rio como um bazar: a conversão da ilegalidade em mercadoria políticas. In: __. Crime e violência no Brasil contemporâneo. Estudos de sociologia do crime e da violência urbana. Rio de Janeiro: Lumen Juris, 2006a. p.211-28.

As ligações perigosas: mercado informal, ilegal, narcotráfico e violência no Rio. In: __. Crime e violência no Brasil contemporâneo. Estudos de sociologia do crime e da violência urbana. Rio de Janeiro: Lumen Juris, 2006b. p.179-210.

O Fantasma e seu duplo. In: Crime e violência no Brasil contemporâneo. Estudos de sociologia do crime e da violência urbana. Rio de Janeiro: Lumen Juris, 2006c. p.269-72.

NAIN, M. Ilícito. O ataque da pirataria, da lavagem de dinheiro e do trafico à economia global. Rio de Janeiro: Zahar, 2006.

OLIVEIRA, F. O ornitorrinco. In: Crítica à razão dualista/O ornitorrinco. São Paulo: Boitempo, 2003.

PORTES, A.; CASTELLS, M. World Underneath: the origins, dynamics, and effects of the informal economy. In: PORTES, A. et al. (Org.) Informal Economy-studies in advanced and less developed countries. Baltimore: Jonhs Hopkings University Press, 1989.

RUGGIERO, V. Crime and makets. Essays in anti-criminology. Oxford: Oxford University Press, 2000.

. Securité et criminalité économique. In: KOKOREFF, M. et al. (Org.) Economies criminelles et mondes urbains. Paris: PUF, 2007. p.121-35.

RUGGIERO, V.; SOUTH N. The late city as a bazaar: drug markets, illegal enterprise and the barricades. The British Journal of Sociology, v.48, n.1, p.54-70, 1997.

SASSEN, S. New York city's informal economy. In: PORTES, A. et al. (Org.) Informal Economy-studies in advanced and less developed countries. Baltimore: Jonhs Hopkings University Press, 1989.

TELLES, V. S. Linha de sombra, tecendo as tramas da cidade. In: OLIVEIRA, F.; RIZEK, C. (Org.) A era da indeterminação. São Paulo: Boitempo, 2007. p.195-218.

TELLES, V. S.; CABANES, R. (Org.) Nas tramas da cidade. Trajetórias urbanas e seus territórios. São Paulo: Humanitas, 2006.

ZALUAR, A. Integração perversa: pobreza e trafico de drogas. Rio de Janeiro: FGV Editora, 2004.

RESUMO - Neste artigo, pretende-se abordar o tráfico de drogas a partir de suas capilaridades no mundo social e nas tramas urbanas, tomando como "posto de observação" alguns de seus pontos de ancoramento na periferia da cidade de São Paulo. Essa é uma perspectiva descritiva (e analítica) que permite situar as práticas criminosas nas suas relações com o que poderíamos definir como a gestão das ilegalidades inscritas nos agenciamentos concretos da vida cotidiana. A rigor, esse é o foco da discussão a ser 
desenvolvida: as evidências de uma crescente e expansiva trama de ilegalidades (nova e velhas) entrelaçadas nas práticas urbanas, seus circuitos e redes sociais, e que são urdidas nas relações hoje redefinidas (e a serem bem compreendidas) entre o ilegal, o informal e o ilícito. Com base em resultados de pesquisa recente, o artigo pretende o exercício de "etnografia experimental" para tentar flagrar as mediações e conexões pelas quais esses deslocamentos das fronteiras do legal e do ilegal vêm se processando. São essas conexões e mediações que precisam ser bem compreendidas: é nelas que se tem uma chave para identificar e compreender a porosidade entre o legal e ilegal, e as fronteiras borradas entre o trabalho, expedientes de sobrevivência e práticas ilícitas; é nelas que se podem identificar e compreender as capilaridades do tráfico de drogas no mundo social, capilaridades urdidas nessas formas de junção e conjugação da trama urbana.

PALAVRAS-CHAVES: Práticas urbanas, Relações entre o informal, o ilegal e o ilícito, Tráfico de drogas, Ilegalidades urbanas.

ABSTRACT - This article intends to approach the drug trade from the perspective of its capillary network in the social world and in urban weaves, using one of its trafficking points in São Paulo's periphery as an "observation station". This is a descriptive (and analytic) perspective that allows us to consider criminal practices in relation to what could be defined as the illegality management, which is present in concrete every-day life administration practices. This is, indeed, the focus of the discussion: evidences of a growing and expansive mesh of illegalities (both old and new ones), their circuits and social networks, which are woven in urban practices and warped in the redefined relations among the illegal, the informal and the illicit. Based on the results of a recent research, the article aims to put an "experimental ethnography" into practice, in an attempt to find out the mediations and connections through which the movements of the boundaries between the legal and the illegal have been taking place. These connections and mediations must be well understood for they contain the key to identifying and understanding the porosity existent between the legal and the illegal, and the blurry boundaries among work, survival expedients and illicit practices. In them, one may identify and comprehend the capillary network of the drug trade in the social world, which is warped in the junctions and conjunctions of the urban weave.

KEYWORDS: Urban practices, Relations among the informal, the illegal and the illicit, Drug trade, Urban illegalities.

Vera da Silva Telles é professora do Departamento de Sociologia da Universidade de São Paulo e pesquisadora do Centro de Estudos dos Direitos da Cidadania (Cenedic). Publicou recentemente, em conjunto com Robert Cabanes, Nas tramas da cidade: trajetórias urbanas e seus territórios (Humanitas, 2006). @ - tellesvs@uol.com.br

Daniel Veloso Hirata é mestre em Sociologia e pesquisador do Cenedic @ - veloso.daniel@uol.com.br

Artigo recebido em 29.8.2007 e aceito em 3.9.2007. 